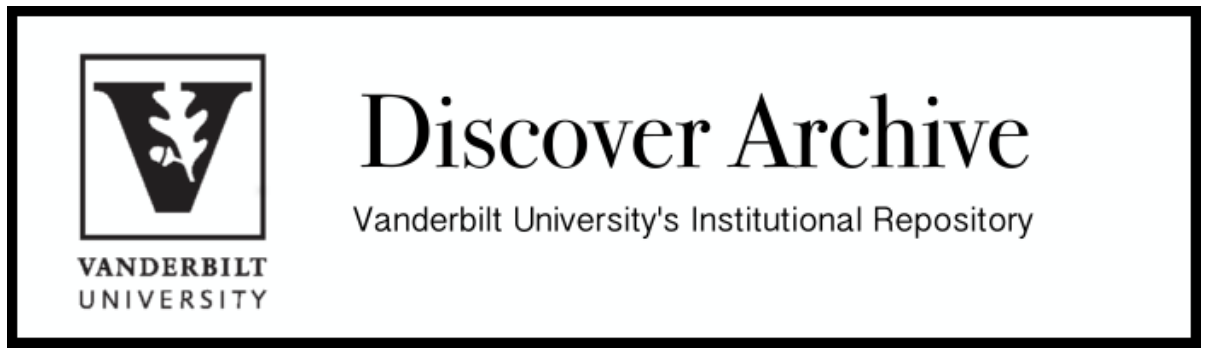

This work was originally published as: W. Kip Viscusi and Ted Gayer, Behavioral Public Choice: The Behavioral Paradox of Government Policy - 38 Harvard Journal of Law \& Public Policy 973 (2015). 


\section{HEINONLINE}

Citation: 38 Harv. J. L. \& Pub. Pol'y 9732015

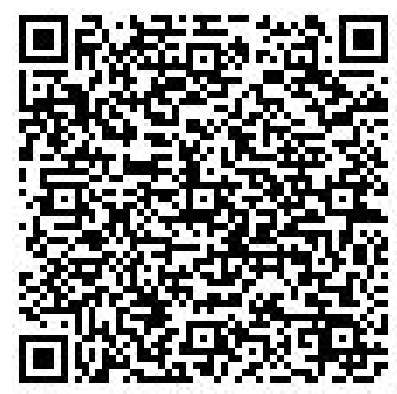

Content downloaded/printed from HeinOnline (http://heinonline.org) Mon Dec 14 16:44:39 2015

-- Your use of this HeinOnline PDF indicates your acceptance of HeinOnline's Terms and Conditions of the license agreement available at http://heinonline.org/HOL/License

-- The search text of this PDF is generated from uncorrected OCR text.

-- To obtain permission to use this article beyond the scope of your HeinOnline license, please use:

https://www.copyright.com/ccc/basicSearch.do? \&operation $=$ go\&search Type $=0$ \&lastSearch $=$ simple\&all $=$ on\&titleOrStdNo $=0193-4872$ 


\title{
Behavioral Public Choice: \\ The BehaVioral Paradox of \\ Government POLICY
}

\author{
W. KIP VISCUSI* \& TED GAYER ${ }^{* *}$
}

\section{OVERVIEW}

What are the economic justifications for government intervention in the economy? In a market economy, prices coordinate the activities of buyers and sellers and convey information about the strength of consumer demand for a good and the costs of supplying it. Because trade is voluntary, buyers and sellers only make exchanges when both parties benefit. Under ideal market conditions, this process leads to an efficient allocation of goods without government intervention.

However, economics has long recognized instances in which markets can fail to lead to an efficient outcome. The long-standing view is that either market power or the nonexistence of markets causes market failures. Market power is present when some individuals or firms are price makers (for example, monopolists) rather than participants in a perfectly competitive environment. Such situations typically lead to the production of a less than efficient quantity of goods. The problem of market power is the purview of industrial organization economics and antitrust policy. ${ }^{1}$

The nonexistence of markets, or the failure of a robust market to arise, can occur for a number of reasons, such as asymmetric information (when one party in a transaction has information that is not available to another) and public goods (when a good is nonrival and nonexcludable in consumption and thus likely to be un-

\footnotetext{
* University Distinguished Professor of Law, Economics, and Management, Vanderbilt Law School, 131 21st Ave. South, Nashville, TN 37203. kip.viscusi@ vanderbilt.edu. We are grateful to the Mercatus Center for their support.

** Vice President and Director, Economic Studies, Brookings Institution, 1775 Massachusetts Ave. NW, Washington, DC 20036. tgayer@brookings.edu.

1. HaRvey S. Rosen \& Ted Gayer, PUblic FinANCE 46-48 (10th ed. 2013).
} 
dersupplied by the market). Another cause for the nonexistence of markets is externalities, which occur when transactions impose costs or benefits on a third party that are not considered in the market exchange. A classic example is when a factory produces and sells a good to a consumer to their mutual advantage, but the pollution generated by the production of the good has a negative impact on the health of nearby residents. A market for the clean air in the affected area would not emerge if high transaction costs of organizing the pollution victims prevented the parties from negotiating. ${ }^{2}$ The market system will fail to internalize the health costs imposed by the factory's operations and lead to inefficiently high production and health consequences.

For about a century, economists have argued that policymakers should rely, when possible, on market-based principles in designing regulations to address these market failures. For example, in the pollution cases above, a tax on production equal to the marginal external costs could lead producers to internalize the thirdparty costs stemming from production, which would result in an efficient outcome. ${ }^{3}$ Similarly, establishing a property right for the clean air (for example, through a cap-and-trade program) could also cause producers to internalize the third-party costs in their market decisions, again resulting in an efficient outcome.

But in recent years, economics has seen a change from the traditional approach of evaluating market failures and in the justifications for government intervention in the economy, with implications for when and how the government should intervene. Recent research has focused on identifying cognitive limitations and psychological biases that lead people to make choices that cause self-harm, thus suggesting another type of market failure that justifies government intervention. ${ }^{4}$ We refer to these phenomena as behavioral failures in that they often involve departures from the individual rationality assumptions incorporated in economists' models of consumer choice.

2. See generally R. H. Coase, The Problem of Social Cost, 3 J.L. \& ECON. 1 (1960).

3. ROSEN \& GAYER, supra note 1 , at 84-85.

4. As is common in the behavioral economics literature, we classify cognitive limitations and psychological biases as market failures, even though they reflect problems with individual preferences, not systemic problems with the incentives and institutions that represent the traditional market failures. 
William Congdon, Jeffrey Kling, and Sendhil Mullainathan classify deviations from standard economic assumptions found in psychology and behavioral economics into three categories: imperfect optimization, bounded self-control, and nonstandard preferences. ${ }^{5}$ Imperfect optimization challenges the traditional economics view that people are good at making decisions concerning their own well-being. For example, one study suggests that people are less likely to participate in their employer's retirement plan as the number of investment alternatives rises, thus suggesting that a government policy of limiting options could improve welfare. ${ }^{6}$ Another study finds that the salience of a sales tax (which differs depending on whether the tax is included in the sticker price or computed at the register) influences the behavior of consumers, even though the net price the consumer pays is the same in both cases.

Bounded self-control challenges the traditional economics view that, even when people know what they want, they are unable to act on these interests. These bounded self-control findings include evidence of procrastination and succumbing to immediate temptation, both of which can result in self-harm. ${ }^{8}$ The nonstandard preferences phenomenon challenges some of the standard economic assumptions about choice, such as that people value the end state rather than the path taken to achieve an outcome. For example, psychology and behavioral economics find that people value a good differently depending on whether they were ran-

5. WILliam J. CONGDON, JeFFREY R. KLING \& SENDHIL Mullainathan, POlICY aND CHOICE: PUBLIC FINANCE THROUGH THE LENSOF BEHAVIORAL ECONOMICS 7 (2011).

6. See Sheena Sethi-Iyengar, Gur Huberman \& Wei Jiang, How Much Choice is Too Much? Contributions to 401(k) Retirement Plans, in PENSION DESIGN AND STRUCTURE: NEW LESSONS FROM BEHAVIORAL FINANCE 83, 88-91 (O.S. Mitchell \& S. Utkus eds., 2004). Some more recent articles have argued that this apparently flawed decision making when confronting seemingly excessive choices may be a rational response to nonzero search costs not taken into account by Sethi-Iyengar et al. See Dmitri Kuksov \& J. Miguel Villas-Boas, When More Alternatives Lead to Less Choice, 29 MARKETING SCIENCE 507, 519 (2010).

7. Raj Chetty, Adam Looney \& Kory Kroft, Salience and Taxation: Theory and Evidence, 99 AM. ECON. REV. 1145, 1175 (2009).

8. CONGDON, KLING \& MULLAINATHAN, supra note 5, at 7. 
domly endowed with the good, ${ }^{9}$ and also that people do not value losses and comparable gains symmetrically. ${ }^{10}$

Reasonable critiques of the behavioral economics findings abound. For example, many of the findings of deviation from rational behavior take place in laboratory or field experiment settings. Nobel laureate economist Gary Becker is critical of the relevance of this practice, noting that "there is a heck of a difference between demonstrating something in a laboratory, in experiments, even highly sophisticated experiments, and showing that they are important in the marketplace."11 Becker also points out that "some of the defects in behavior claimed by behaviorists tend ... to be eliminated in an exchange economy." 12 Indeed, one study of the market for sports memorabilia finds that the market experience of card traders leads to the elimination of the endowment effect. ${ }^{13}$ Further, some of the findings suggesting irrationality are questioned among psychologists. One study concluded that the "conjunction fallacy"14 found in some psychological studies is due to the wording used in the experiments (such as using "probable" instead of "relative frequencies") and contextual interpretation by the participants rather than a failure of logic. ${ }^{15}$

In this Article we examine a wide range of behavioral failures, such as those linked to misperception of risks, unwarranted aversion to risk ambiguity, inordinate aversion to losses, and inconsistencies in the tradeoffs reflected in individual decisions. Alt-

9. See Daniel Kahneman, Jack L. Knetsch \& Richard H. Thaler, Experimental Tests of the Endowment Effect and the Coase Theorem, 98 J. OF POL. ECON. 1342, 1343 (1990).

10. See generally Daniel Kahneman \& Amos Tversky, Prospect Theory: An Analysis of Decision under Risk, 47 ECONOMETRICA 263 (1979).

11. Douglas Clement, Interview with Gary Becker, THE REGION, June 1, 2002, https:// www.minneapolisfed.org/publications/the-region/interview-with-gary-becker [http:// perma.cc/23VU-99LJ].

12. Id.

13. John A. List, Does Market Experience Eliminate Market Anomalies?, 118 Q.J. ECON. 41, 70-71 (2003).

14. The "conjunction fallacy" is a phenomenon whereby experimental subjects appear to assess the probability of A and B together as being more likely than the probability of A generally-a logical impossibility. For example in the famous "Linda problem" subjects are given a profile of Linda as a young outspoken intellectual involved in social causes and indicate that it is more likely that Linda is a bank teller and a feminist than that she is a bank teller.

15. Ralph Hertwig \& Gerd Gigerenzer, The 'Conjunction Fallacy' Revisited: How Intelligent Inferences Look Like Reasoning Errors, 12 J. BEHAVIORAL DECISION MAKING 275, 276, 300 (1999). 
hough such shortcomings have been documented in the behavioral literature, they are also reflected in government policies, both because policymakers are also human and because public pressures incorporate these biases. The result is that government policies often institutionalize rather than overcome behavioral anomalies. This idea is the principal theme of Viscusi's Rational Risk Policy, which documents a wide range of parallels between the systematic failures in risky private decisions and government risk policies. ${ }^{16}$ These institutional irrationalities pertain quite generally to government policies and are not restricted to regulations directly affecting consumer behavior. In this Article, we also find that the government often relies on command-and-control regulation, even when the insights of the behavioral literature counsel a more flexible regulatory approach.

\section{BeHAVIORAL PUBlic CHOICE THEORY}

This Article examines the common policy implications-not the specific empirical findings - of the behavioral economics literature, which frequently recommends "soft paternalism" policies that seek to change the structure of the choices available to individuals in order to encourage a more desirable outcome. But, as behavioral agents themselves, policymakers and regulators are subject to the same psychological biases and limitations as all individuals. ${ }^{17}$ Many, although certainly not all, behavioral economics papers focus on the biases and heuristics of ordinary individuals, while seemingly ignoring that regulators are people too and thus subject to the same psychological forces. One study finds that, of the behavioral economics articles proposing paternalistic policy responses, $95.5 \%$ do not contain any analysis of the cognitive abilities of policymakers. ${ }^{18}$ Congdon, Kling, and

16. W. KIP VISCUSI, RATIONAL RISK POLICY (1998). See also W. Kip Viscusi \& James Hamilton, Are Risk Regulators Rational? Evidence from Hazardous Waste Cleanup Decisions, 89 AM. ECON. REv. 1010 (1999). For a further discussion of how behavioral anomalies among the citizenry can impact public policy, see generally BRYAN CAPLAN, THE MYTH OF THE RATIONAL VOTER: WHY DEMOCRACIES CHOOSE BAD POLICIES (2008).

17. See generally Slavisa Tasic, Are Regulators Rational?, 17 J. DES ECONOMISTES ET DES ETUDES HUMAINES 1145 (2011); Slavisa Tasic, The Illusion of Regulatory Competence, 21 CRITICAL REV. 423 (2009).

18. Niclas Berggren, Time for behavioral political economy? An analysis of articles in behavioral economics, 25 REV. AUSTRIAN ECON. 199, 200 (2012). 
Mullainathan acknowledge that "behavioral economics creates something of a paradox in requiring more of policymakerssuch as new judgments about identifying and distinguishing behavioral tendencies-while suggesting that policymakers' capacity to make such judgments may be impaired to the extent that they too are behavioral agents." 19 Unfortunately, they subsequently put this view aside. Similarly, Professor Cass Sunstein observes, "For every bias identified for individuals, there is an accompanying bias in the public sphere." 20

The question then is whether private decision makers acting in the marketplace are more or less prone to psychological biases than are the public decision makers who regulate the economy, whether through traditional regulations or through "nudges" that seek to change the choice architecture in a way that leads people to choose more optimal actions. This approach parallels the traditional public finance calculus of weighing the inefficiencies caused by market failures against the inefficiencies caused by government failures in attempting to address market failures through regulations. ${ }^{21}$

There are two main reasons why regulatory responses motivated by behavioral economics findings might be suboptimal. ${ }^{22}$ The first, as already mentioned, is that as behavioral agents themselves, regulators are not immune from the psychological biases that affect ordinary people. The second is that policymakers are subject to public choice incentives that could further lead to policies that reduce welfare, and indeed could lead to the misuse of behavioral findings by regulators in order to enhance regulatory control or favor the influence of powerful special interests over

19. CONGDON, KLING \& MULLAINATHAN, supra note 5, at 56.

20. Cass R. Sunstein, Why Nudge? The Politics of Libertarian PaternalISM 102 (2012).

21. See generally CLIFFORD WINSTON, GOVERNMENT FAILURE VERSUS MARKET FAILURE: MICROECONOMIC POLICY RESEARCH AND GOVERNMENT PERFORMANCE (2006).

22. For additional views of the problems with basing regulations on behavioral economics findings, see generally Robert Sugden, Why incoherent preferences do not justify paternalism, 19 CONST. POL. ECON. 226 (2008) (arguing that mutual advantage aspect of market transactions does not require coherent preferences) and Jayson L. Lusk, Are you smart enough to know what to eat? A critique of behavioral economics as justification for regulation, 41 EUR. REV. OF AGRIC. ECON. 355 (2014) (arguing that cognitive biases alone do not justify regulatory intervention). 
the interests of public welfare. ${ }^{23}$ By focusing on these two issues, this Article seeks to answer Sunstein's call for the creation of a field in "behavioral public choice theory." 24

There are a number of public choice arguments about why private decision making might be less prone to errors than public decision making. ${ }^{25}$ The most obvious argument is that psychological failings in citizens would suggest bad decision making in their voting practices at least as much as in their market transactions. To the extent that policies are decided through a majority voting system, then under certain conditions, the median voter will determine the policy response. ${ }^{26}$ If the median voter is subject to behavioral biases as suggested by the psychology literature, then the resulting policy is likely to be suboptimal. In other words, in a democratic system, theory and evidence suggest that government policies will reflect the irrationalities of ordinary people. ${ }^{27}$

Public choice theory also suggests that private decision makers have stronger incentives to acquire informationexpending both time and money - to overcome behavioral biases, since the personal costs to a citizen who makes a bad decision are higher than the personal costs to the regulator of a rule that leads to a bad outcome for that citizen. There is some experimental evidence that, at least for some kinds of decisions, people with incentives can partially reduce cognitive biases through learning, ${ }^{28}$ and given that the costs of cognitive biases weigh more on the citizen than on the regulator, one should expect fewer errors among private than among public decision makers. Finally, public choice studies have also found that,

23. GORDON TULLOCK, ARTHUR SELDON \& GORDON L. BRADY, GOVERNMENT FAILURE: A PRIMER IN PUBLIC CHOICE 87 (2002).

24. SUNSTEIN, supra note 20, at 100.

25. For a summary, see generally Edward L. Glaeser, Paternalism and Psychology, 29 REGULATION 32 (2006)

26. Randall Holcombe, Public Sector ECONOMics: The ROLE OF GOVERNMENT IN THE AMERICAN ECONOMY 155 (2005).

27. See generally Bryan Caplan, supra note 16, at 10; Jan Schnellenbach \& Christian Schubert, Behavioral Political Economy: A Survey (CESifo, Working Paper No. $4988,2014)$.

28. See Colin F. Camerer \& Robin M. Hogarth, The Effects of Financial Incentives in Experiments: A Review and Capital-Labor-Production Framework, 19 J. RISK \& UNCERTAINTY 7, 34-35 (1999). 
where a policy has high but diffuse costs and low but concentrated benefits (such as a trade-liberalizing policy that improves net benefits, but does so by providing small benefits to many consumers while providing concentrated costs to a few producers), the stronger incentives of the few may have greater influence than the preferences of the many, possibly leading to inefficient policies. ${ }^{29}$ This tendency would suggest that government policies aimed at addressing the deliberate manipulation of the choice architecture that occurs in the marketplace are also prone to deliberate manipulation by regulators in a way that leads to suboptimal outcomes.

Our focus on behavioral public choice suggests a need for caution in using the findings of individual biases to justify greater government intervention, even for soft paternalism policies that seek to protect a degree of individual choice. This is not to suggest that all behavioral justifications for government intervention are invalid and inevitably prone to misuse. Daniel Kahneman considers two modes of thinking: System 1 "operates automatically and quickly, with little or no effort and no sense of voluntary control," while System 2 "allocates attention to the effortful mental activities that demand it, including complex computations." 30 The biases that lead to suboptimal personal behavior typically result from actions dominated by the "freewheeling impulses" of our System 1 rather than the "conscious, reasoning self" of System 2. ${ }^{31}$ Behavioral economists who advocate for more soft paternalism policies are essentially motivated by the belief that government technocrats are, by nature, training, and employment, disposed toward System 2 thinking and can therefore design policies that overcome the problems caused by System 1 reasoning. ${ }^{32}$ Some critics, however, contend that the narrowness of the expertise of government technocrats will subject them to overconfidence caused by the illusion of explanatory depth, ${ }^{33}$ that such experts will have a limited and biased understanding compared to the information pro-

29. See Gary S. Becker, A Theory of Competition Among Pressure Groups for Political Influence, 98 Q.J. ECON. 371,392 (1983).

30. DANIEl KahNEMAN, THINKING, FAST AND Slow 20-21 (2011).

31. Id. at 21.

32. Id at 48.

33. See Tasic, Illusion, supra note 17 , at 430 . 
vided by a more decentralized approach, ${ }^{34}$ and that the use of government nudges to limit individual choice will reduce autonomy, dignity, and the motivation of individuals to engage and nurture their System 2 reasoning. ${ }^{35}$ The behavioral public choice approach seeks to weigh the political incentives and psychological biases of government decision making and critique the optimistic view of a government composed of well-meaning technocrats who are better equipped than ordinary citizens to overcome purported System 1 biases.

\section{BEHAVIORAL RATIONALES FOR GOVERNMENT POLICY}

The prominent role of behavioral rationales for government regulation is exemplified by the recent wave of government initiatives by the U.S. Department of Energy (DOE), the U.S. Environmental Protection Agency (EPA), and the U.S. Department of Transportation (DOT) mandating energy-efficiency levels for many major consumer durable goods. In an earlier paper, we examined these regulations and found that the traditional market failure justifications (for example, externalities and asymmetric information) are incidental to an assessment of the merits of these regulations. ${ }^{36}$ Rather, the agencies justify these regulations based on the contention that consumers suffer from psychological biases that lead them to make irrational choices in their purchases of durables.

There is a long-standing empirical finding, known as the energy-efficiency gap, which shows that consumer choices for energy-efficiency purchases imply a discount rate much higher than market discount rates. This finding suggests that consumers underestimate the future cost savings stemming from an energy-efficient product compared to the weight they put on future savings in other market settings. ${ }^{37}$ This apparent bias could

34. See F. A. Hayek, The Use of Knowledge in Society, 35 AM. ECON. REV. 519, 524 (1945).

35. Jeremy Waldron, It's All for Your Own Good, N.Y. REV. OF BOOKS, Oct. 9, 2014, http://www.nybooks.com/articles/archives/2014/oct/09/cass-sunstein-its-all-yourown-good/ [http://perma.cc/Y9]P-ATEX]; Steven Poole, Not so foolish, AEON (2014).

36. Ted Gayer \& W. Kip Viscusi, Overriding consumer preferences with energy regulations, 43 J. REG. ECON. 248, 249 (2013).

37. See, e.g., Jerry A. Hausman, Individual Discount Rates and the Purchase and Utilization of Energy-Using Durables, 10 BELL J. OF ECON. 33, 50-52 (1979). Recent 
arise from irrational consumer behavior driven by psychological heuristics. Some studies find evidence that people make decisions regarding which appliances to purchase based on current energy prices rather than on expected future prices, leading to a tendency to forgo purchasing energy-efficient products. ${ }^{38}$ However, other studies find that consumers reasonably base their forecasts of energy prices on current prices and therefore do not present a behavioral market failure. ${ }^{39}$ Yet other studies find that the psychological "salience" of the more expensive, efficient appliance leads to underinvestment in energy efficiency. ${ }^{40}$

However, alternative explanations for the energy-efficiency gap exist that are consistent with individual rationality. The observed consumer choice may simply reflect actual consumer preferences. ${ }^{41}$ For example, the high implied discount rates could be a rational response to high sunk costs and uncertainty over future conservation savings. ${ }^{42}$ If you are planning to move or you have a liquidity problem, buying the more energy-efficient but more expensive appliance may not make sense. Many of the studies purporting to show that consumers forgo profitable energy decisions are based on engineering studies that calculate the net present value of a set of possible energy-efficiency consumption choices, which requires assumptions concerning such things as capital costs, current and future energy prices, duration and frequency of appliance use, and discount rates. ${ }^{43}$ These studies omit other relevant costs or benefits that can drive the purchase decision.

studies suggest little evidence of consumer myopia with respect to automobile fuel economy. See Meghan R. Busse, Christopher R. Knittel \& Florian Zettelmeyer, Are Consumers Myopic? Evidence from New and Used Car Purchases, 103 AM. ECON. REV. 220, 221 (2013).

38. Willett Kempton \& Laura Montgomery, Folk Quantification of Energy, 7 ENERGY 817, 822-23, 826 (1982).

39. Soren T. Anderson, Ryan Kellogg \& James M. Sallee, What Do Consumers Believe About Future Gasoline Prices? 2 (Nat'l Bureau of Econ. Research, Working Paper No. 16974, 2011).

40. Charlie Wilson \& Hadi Dowlatabadi, Models of Decision Making and Residential Energy Use, 32 ANN. REV. OF ENV'T \& RESOURCES 169, 175 (2007).

41. Jerry A. Hausman \& Paul L. Joskow, Evaluating the Costs and Benefits of Appliance Efficiency Standards, 72 AM. ECON. REV. 220, 222 (1982).

42. Kevin A. Hassett \& Gilbert E. Metcalf, Energy conservation investment: Do consumers discount the future correctly?, 21 ENERGY POL'Y 710, 710 (1993).

43. See, e.g., MCKINSEY \& CO., ELECTRIC POWER AND NATURAL GAS: UNLOCKING ENERGY EFFICIENCY IN THE U.S. ECONOMY, July 2009, http://www.mckinsey.com/ 
Another possible explanation for the energy-efficiency gap findings is that consumers do not expect to receive as high a return in energy savings as the regulatory analyst assumes. This might be the case if, for instance, engineering estimates of potential savings misrepresent energy savings because they are based on highly controlled studies that do not directly apply to actual realized savings in a representative house. There is some evidence that engineering estimates of energy savings are indeed faulty. ${ }^{44}$ For example, Gilbert Metcalf and Kevin Hassett find that the realized return on attic insulation falls short of the returns promised by engineers and product manufacturers. ${ }^{45}$ Accounting for this discrepancy eliminates the paradox of the energy-efficiency gap in this situation. ${ }^{46}$

Another approach to measuring the energy-efficiency gap is to use empirical studies of energy-use data to estimate the average returns for the set of consumers that adopt an energyefficient technology, such as by comparing natural-gas billing data in the first year after weatherization work is done to the same data from the previous year. In addition to the problem associated with a short-time horizon, these studies also suffer from the common pitfalls associated with omitted variable bias in which other key factors affecting the decision are ignored. As Hunt Allcott and Michael Greenstone explain, such studies can omit many relevant costs and benefits. ${ }^{47}$ For example, weatherizing a home can be a time-consuming and unpleasant task for the homeowner. Weatherization can also yield benefits not measured by billing data, such as greater home comfort. Failing to account for these factors that contribute to the consumption decision can lead to spurious findings of an energy-efficiency gap.

clientservice/electricpowernaturalgas/downloads/US_energy_efficiency_full_ report.pdf [http://perma.cc/3KXK-GY5F].

44. Steve Nadel \& Kenneth Keating, Engineering Estimates vs. Impact Evaluation Results: How Do They Compare and Why? 3, 6 (Research Report U915, American Council for an Energy-Efficient Economy, January 1, 1991), available at http:// www.aceee.org/research-report/u915 [http://perma.cc/UM7C-42B7].

45. Gilbert E. Metcalf \& Kevin A. Hassett, Measuring the Energy Savings from Home Improvement Investments: Evidence from Monthly Billing Data, 81 REV. OF ECON. \& STAT. 516, 516 (1999).

46. Id. at $516,527$.

47. Hunt Allcott \& Michael Greenstone, Is There an Energy Efficiency Gap? 14 (Mass. Inst. of Tech., Working Paper No. 12-03, January 1, 2012). See also Hunt Allcott, Consumers' Perceptions and Misperceptions of Energy Costs, 101 AM. ECON. REV. 98 (2011). 
Taken as a whole, the literature on the energy-efficiency gap does not provide strong, credible evidence of persistent consumer irrationality. Nonetheless, government agencies justified the energy-efficiency mandates on the basis of correcting consumer irrationality, even though they offer little or no evidence that consumers are causing self-harm in their purchasing decisions concerning the regulated consumer durables. Again, in an earlier paper, we found that the preponderance of the estimated benefits stemming from most energy-efficiency regulations derive from this presumption of addressing consumer irrationality, not from reducing the external costs associated with energy use. ${ }^{48}$ For example, for the recent fuel economy mandates for passenger cars and light trucks, the Department of Transportation estimated a total cost of $\$ 177$ billion and a total benefit of $\$ 521$ billion. ${ }^{49}$ Of the $\$ 521$ billion in benefits (assuming a discount rate of three percent and constant 2009 dollars), fully $\$ 440$ billion (or eighty-five percent) stems from the purported benefits of addressing consumer irrationality. ${ }^{50}$ The evidence that consumers undervalue fuel economy is very weak, and the upper bound estimates of consumer misperceptions suggest benefits much smaller than those estimated by the regulatory agencies. ${ }^{51}$ For the same rule, the Environmental Protection Agency estimated that eighty-seven percent of the total benefits (estimated at $\$ 613$ billion) were due to addressing consumer irrationality. We found that the purported need to address consumer irrationality was also a large driver in other energy-efficiency regulations, including fuel economy standards for heavy-duty vehicles, clothes dryers, room air conditioners, and incandescent light bulbs. ${ }^{52}$

This approach by the agencies to justify their regulations based on weak evidence of consumer irrationality illustrates a key negative consequence of misusing behavioral findings: the welfare loss associated with ignoring heterogeneous preferences. The one-size-fits-all approach that ignores potential heterogenei-

48. Gayer \& Viscusi, supra note 36, at 249.

49. Id. at 251 .

50. Id.

51. Hunt Allcott, The Welfare Effects of Misperceived Product Costs: Data and Calibrations from the Automobile Market, 5 AM. ECON. J.: ECON. POL'Y 30, 32 (2013).

52. Gayer \& Viscusi, supra note 36 , at 257-63. 
ty in consumer preferences is most common in command-andcontrol regulations (such as energy-efficiency mandates), but even the soft paternalism approach steers all people in the same direction. Differences in preferences and income generate different levels of consumer demand for products. Even for products all consumers might find attractive, there will be differences in preference; some consumers are willing to pay more for the product than others, giving rise to the usual downward-sloping demand for the product. There will also be more extreme situations in which some consumers may not want a product at any price even though others may value it, as in the case of vegetarians who do not wish to consume meat. In recognition of such differences, the market often generates highly differentiated products, ranging for instance from very basic automobiles, which serve as a functional form of transportation, to luxury cars. Homogenizing these choices through command-andcontrol regulations, or even through more subtle manipulation of the choice architecture, imposes costs on those with preferences outside of the allowable options.

The fuel economy mandate also provides evidence in support of William Niskanen's public choice view that regulators will attempt to maximize their authority rather than social welfare..$^{53}$ The behavioral economics approach recommends soft paternalism options over regulations. Indeed, a broad reading of this literature counsels in favor of many welfare-improving policies that change existing hard regulations to soft, nudge-like regulations. In other words, behavioral economics does not and should not only justify more traditional government interventions; in many cases it should justify a reduction in regulatory power. Public choice theory, however, suggests that regulators would be more prone to use behavioral findings to justify increasing regulatory power than to move toward softening regulations.

The fuel economy regulation is a case in point. The EPA's and DOT's analyses find that the preponderance of the benefits stem from correcting purported consumer irrationality, not from reducing externalities. This raises the question of why a rigid mandate is warranted rather than an informational regu-

53. William A. NisKaneN JR., BUREAUCRACY AND REPRESENTATIVE GOVERNMENT 36 (1971). 
lation that would nudge consumers to make sounder choices. Indeed, in 2011 the EPA did just that by issuing its Motor Vehicle Fuel Economy Label Final Rule. ${ }^{54}$ The mandated label for all new cars is quite extensive, including an overall miles per gallon (mpg) rating, a city mpg rating, a highway mpg rating, gallons per 100 miles, driving range on a tank of gas, fuel costs in five years versus the average new vehicle, annual fuel costs, fuel economy and greenhouse gas rating, and smog rating. ${ }^{55}$ These components of the label address the purported behavioral failures in that they (i) indicate the longer-term fuel costs, thus diminishing the effect of high discount rates, (ii) make the benefits of fuel economy salient and a less "shrouded" attribute, (iii) provide easy calculations of fuel economy, (iv) enable consumers to understand the actual fuel economy benefits rather than relying on rough rules of thumb, $(v)$ make it clear that fuel economy is a valued vehicle attribute, not a proxy for a less expensive vehicle, (vi) make it easier for consumers to identify which vehicles provide fuel economy, (vii) provide diverse measures of fuel economy that consumers can relate to their driving style, and (viii) make the fuel costs more apparent as an upfront cost similar to the sticker price of a vehicle. Indeed, the EPA label rule is directed at remedying almost all of the types of consumer choice failures that the EPA claims account for the private benefits of fuel economy standards.

What is striking about the EPA's regulatory impact analysis of the fuel economy mandates is that it does not even mention the existence of the agency's own new label rule. ${ }^{56}$ This oversight goes to the heart of the fuel economy standard analysis, as most of the benefits needed to justify the regulation relate to consumer choice failures targeted by the new labeling rule. The EPA analysis of the fuel economy mandate should address the effectiveness of the label rule and the degree to which it ameliorates the need for an additional mandate. It is not necessarily

54. Revisions and Additions to Motor Vehicle Fuel Economy Label Final Rule, 76 Fed. Reg. 39, 478 (July 6, 2011).

55. Id. at 39, 478-80.

56. U.S. ENVIRONMENTAL PROTECTION AGENCY, EPA-420-R-12-016, REGULATORY IMPACT ANALYSIS: FINAL RULING FOR 2017-2025 LIGHT-DUTY VEHICLE GREENHOUSE GAS EMISSIONS STANDARDS AND CORPORATE AVERAGE FUEL ECONOMY STANDARDS (2012). 
inconsistent to have both a labeling rule and a fuel economy mandate, but any assessment of the desirability of a fuel economy should take into account the impact of the labeling regulation and the role of differences in consumer preferences. If the label rule is completely worthless and generates no benefits for consumer choice, then the EPA was remiss in issuing the regulation, and the Office of Management and Budget, the watchdog over all major new federal regulations, was remiss in permitting the agency to move forward with a rule that other EPA assessments implicitly treat as worthless. ${ }^{57}$

Although the agencies' analyses of the energy-efficiency standards invoke broad references to the behavioral economics literature to justify their presumption of consumer irrationality, nowhere in these analyses do they invoke behavioral findings that could suggest a diminished need for regulation. For example, findings from the psychology and behavioral economics literature suggest that people care about the outcomes realized by others. These other-regarding preferences mean that people might voluntarily internalize the costs of their actions to others, mitigating the need for regulations to address pollution externalities. The existence of other-regarding preferences would also suggest approaches other than mandates to reduce energy use. Indeed, some studies suggest that economic incentives can discourage prosocial, other-regarding behavior, ${ }^{58}$ undermining the standard economic argument for pollution taxes to address externalities. $\mathrm{Nu}-$ merous findings suggest that social norms influence individual behavior, including one study that found evidence of a "conspicuous conservation effect," in which people value the "green halo" signal of owning a Prius over other, more traditional-looking hybrid vehicles. ${ }^{59}$ Other studies suggest that providing feedback to customers on energy use with a focus on peer comparisons leads

57. Cf. John D. Graham \& Cory R. Liu, Regulatory and Quasi-Regulatory Activity Without OMB and Cost-Benefit Review, 37 HARV. J.L. \& PUB. POLY 425, 431-39 (2014).

58. See, e.g., Roland Bénabou \& Jean Tirole, Incentives and Prosocial Behavior, 96 AM. ECON. REV. 1652, 1654 (2006).

59. Steven E. Sexton \& Alison L. Sexton, Conspicuous Conservation: The Prius Effect and Willingness to Pay for Environmental Bona Fides 1-2, 22 (UC Berkeley, Working Paper, 2010). 
to a reduction in energy consumption at a low cost. ${ }^{60}$ Nonetheless, we are not aware of any instances where softer regulations that provide information to influence social norms were considered in the regulatory agencies' analyses of the various energy-efficiency mandates for consumer durables.

\section{FAILURES OF RISK PERCEPTION AND RISK ASSESSMENT}

A major and well-documented class of failures of rationality in individual choices pertains to the assessment and perception of the probability levels of different outcomes. In this Part we focus on behavioral failures linked to what is termed "risk," and in Part V we address closely-related issues concerning ambiguity surrounding risk levels. The risk-related concerns pertain to the absolute levels of a probability and possible changes in these levels, whereas the uncertainty concerns address imprecision and ambiguity involved in the assessed risk levels. We describe how government policies that reflect individual behavioral anomalies with respect to risk and uncertainty lead to suboptimal outcomes.

How risk and uncertainty enter the decision process depends on the decision context and the normative reference point. In the case of government policies, the normative assumption that we adopt in guiding our discussion is that policies should be based on a comparison of the expected costs with the expected benefits, where the probabilities used in these calculations are the mean values of the probabilities. Thus, we assume that the precision of the probabilistic judgments should not be a consideration. It is the best estimate of the probability levels, not the worst-case or best-case assumptions regarding the level of the risk, that should guide risk assessments. ${ }^{61}$

Environmental risks provide an instructive context for considering how probabilities enter the regulatory impact analysis. The expected benefits for EPA regulations often are expressed in terms

60. Ian Ayres et al., Evidence from Two Large Field Experiments That Peer Comparison Feedback Can Reduce Residential Energy Usage 2 (Nat'l Bureau of Econ. Research, Working Paper No. 15386, 2009).

61. We explore possible exceptions to this principle below. In situations in which learning about the probabilities can take place, the precision of the probabilities also enters as a pertinent concern. 
such as the expected number of cancer cases prevented, calculated using the probability of cancer and the size of the exposed population. These expected health effects are then weighted by the agency's monetary valuation of these cancer risks to make the cancer case reduction benefits in the same monetary terms as the regulatory costs, thus facilitating a comparison of the benefits and costs. ${ }^{62}$ One might, of course, choose to adopt a normative policy criterion other than a benefit-cost framework. The biases that we discuss below are also pertinent to addressing behavioral paradoxes with respect to many other policy frameworks not tied to a benefit-cost approach, but it is useful to have a reference point for a concrete policy evaluation to frame our discussion.

One of the best-documented biases people exhibit in thinking about risky choices is in their perceptions of the absolute level of risk. An early example in this literature is the study by Sarah Lichtenstein et al., ${ }^{63}$ which analyzed people's assessment of the level of different mortality risks. They found that the public tends to overestimate low probability risks of death and underestimate large risks. ${ }^{64}$ That is, real threats to health-such as the risks of stroke, cancer, and heart disease - tend to be underestimated, although the less consequential threats-such as the risks of botulism, lightning strikes, and natural disasters - tend to be overestimated. Daniel Kahneman and Amos Tversky incorporated this systematic bias in risk beliefs with respect to the level of the actual risk into their widely used prospect theory model.${ }^{5}$ Note that their model is a predictive framework that indicates how people actually make decisions rather than a normative framework that specifies how they should make decisions. Whether the kinds of departures from economic rationality that are incorporated in the prospect theory model and other behavioral frameworks also affect government policy is a key focus of this Article.

62. These costs and benefits are often quite substantial. See, e.g., OFFICE OF MGMT. \& BUDGET, REPORT TO CONGRESS ON THE BENEFITS AND COSTS OF FEDERAL REGULATIONS AND UNFUNDED MANDATES ON STATE, LOCAL, AND TRIBAL ENTTTIES 13-18 (2014), http://www.whitehouse.gov/sites/default/files/omb/inforeg/2014_cb/ draft_2014_cost_benefit_report-updated.pdf [http://perma.cc/WV4Y-YGDW].

63. See generally Sarah Lichtenstein et al., Judged Frequency of Lethal Events, $4 \mathrm{~J}$. OF EXPERIMENTAL PSYCHOL. 551 (1978).

64. Id. at 574 .

65. See Daniel Kahneman \& Amos Tversky, Prospect Theory: An Analysis of Decision under Risk, 47 ECONOMETRICA 263 (1979). 
The systematic bias in which small risks are overestimated and large risks are underestimated has two additional implications. First, because people tend to overestimate small probabilities, when these small risks are eliminated, they will tend to overestimate the risk reduction that takes place. Similarly, this property creates a substantial potential for overreactions to small risks, such as those posed by weak carcinogens and nanoparticles. If a risk has increased from zero to some small positive value, people will tend to overestimate the extent of the increase. The alarmist reactions to newly discovered carcinogens in food or beverages would fit this profile.

A second ramification of the pattern of overestimating small risks and underestimating large risks is that perceptions in effect flatten out the relationship between perceived risks and actual risks. People may tend to underestimate the change in risk levels for nonzero levels of risk. As a consequence, they will tend to under-assess the benefits derived from risk improvements unless the improvements are successful in eliminating the risk. ${ }^{66}$ Thus, for example, people may tend to underestimate the risk reduction benefits derived from using seat belts, providing a potential impetus for government requirements regarding selfprotection, such as mandating the use of seat belts in cars. ${ }^{67}$

Biased risk perceptions are not limited to private parties. Whether government policy overcomes these types of irrationality linked to the level of the risk probability - or instead institutionalizes them-depends on the strength of public pressures on the agency and the possible presence of similar failures of rationality by government officials. Government agencies could be better suited to making more accurate risk assessments if they have additional and unbiased information about the risks that the general public may not have. Government bureaucrats who have a professional involvement in particular risk areas could have more accurate beliefs because they have obtained more information than the average citizen has about the true risks involved. Government agencies have the expertise and staff to stay

66. VISCUSI, supra note 16, at 25; Viscusi \& Hamilton, supra note 16, at 1010.

67. The presence and extent of such a general perceptional bias does in fact affect the particular decision context and should be corroborated in each instance rather than assuming that all private decisions are necessarily flawed and that the extent of the market failure is sufficient to warrant overriding private decisions. 
informed about the evolving scientific evidence with respect to risk, thus relying more on Kahneman's System 2 thinking when evaluating these risks. There appear to be some benefits to familiarity with risks in terms of being able to make sound risk judgments. For example, survey evidence demonstrates that judges have more accurate risk assessments of various kinds of death than does the general public, as judges tend to overestimate small risks and underestimate large risks to a lesser extent than does the public. ${ }^{68}$ Such superior knowledge is quite plausible, as judges have handled or have read about numerous cases involving accidents and various tort-related hazards.

Unfortunately, in many instances government policies serve to incorporate the same kinds of risk perception biases plaguing individual risk judgments. Thus, government officials' access to additional information does not mean that they take advantage of greater knowledge about risks to form unbiased assessments of risks. There may be systematic biases in agencies' risk assessments toward devoting inordinate attention to worst-case scenarios. The hazardous waste cleanup policy known as the Superfund program is a prominent example.

The EPA approaches the hazardous waste cleanup decision in a systematic manner, assessing the level of the risk posed by a particular site. However, in doing so, the EPA incorporates a series of conservatism biases that tend to lead to an overstatement of the risk level. The agency's assessment of the risk is a product of the level of concentration of a particular chemical, the frequency of exposure to the chemical, the amount of exposure, and the dose-response relationship linking the chemical exposure to an estimated risk, such as cancer. ${ }^{69}$ In particular, the EPA incorporates into the risk assessment an upper bound value for each component of the assessment, such as the highest level of concentration of a chemical identified at the hazardous waste site. The result is that the calculation compounds the conservatism bias. Suppose that the agency calculates the cancer risk at the site by multiplying a series of four parameters, where for each parameter the agency uses the ninety-fifth

68. W. Kip Viscusi, Jurors, Judges, and the Mistreatment of Risk by the Courts, $30 \mathrm{~J}$. OF LEGAL STUD. 107, 131 (2001).

69. JAMES T. HAMILTON \& W. KIP VISCUSI, CALCULATING RISKS? THE SPATIAL AND POLITICAL DIMENSIONS OF HAZARDOUS WASTE POLICY 64 (1999). 
percentile value of the parameter. If all parameters in the risk calculation are ninety-fifth percentile values, the overall risk calculation that compounds these biases has a much lower chance than 0.05 of reflecting the actual risk. If there are four such parameters in the risk calculation that are at the ninetyfifth percentile, the chance that the calculated risk could be as large as the estimated risk value is only $6.25 \times 10^{-6}$, or under $1 / 100,000$. An empirical assessment of the EPA's risk assessment calculations for a large sample of Superfund cases found that, even excluding upward biases in the dose-response relationship that the EPA used, for over two-thirds of the groundwater and soil risk pathways, the agency estimated the risks beyond the ninety-ninth percentile of the actual risk distribution. ${ }^{70}$

Regulatory agencies often rely on estimates of risk that compound conservatism bias. For example, in its evaluation of the risk of methyl mercury, the EPA relied on a reference dose that started with a benchmark dose that is the lowest maternal blood mercury concentration expected to lead to a five percent increase in adverse health outcomes in children. Then, it took the ninety percent lower confidence limit of this benchmark dose and applied an additional safety factor by dividing the dose by ten. ${ }^{71}$

These numerical biases in calculating a risk represent only one class of the many regulatory systematic risk assessment biases with respect to estimating the risk reduction benefits of hazardous waste cleanups. If the policy concern is with protecting people from hazards in an effective manner, as we believe it should be, then the agency should take into account the number of people exposed to the risk, the extent of their exposure, and the extent of their risk reduction. However, the EPA does not incorporate risks to actual populations in the risk assessment practices. Instead, the agency's procedures treat real and hypothetical exposures equally. Thus, in an extreme case of risk overestimation, the EPA would value the risk to a single hypothetically exposed individual in the future as being equivalent to a current risk to a large population. ${ }^{72}$ Treating the hypothetical potential risk as equivalent to

70. Id. at 89 .

71. Ted Gayer \& Robert W. Hahn, The Political Economy of Mercury Regulation, 28 REGULATION 26, 29 (2005).

72. Id. at 91 . 
an actual risk, coupled with a complete disregard for the number of people exposed to the risk, leads to an overestimation of very small risks and comparative inattention to larger risks. As a result, cleaning up Superfund sites that pose real risks to actual populations looks as desirable as cleanups that might affect hypothetical future populations. This bizarre practice caught the attention of now Supreme Court Justice Stephen Breyer ${ }^{73}$ While serving as an appellate court judge, he encountered a Superfund cleanup case, United States $v$. Ottati \& Goss, Inc., ${ }^{74}$ in which the rationale for the cleanup was to prevent children from eating the contaminated dirt. Breyer was puzzled, however, as to why the EPA would be undertaking such a cleanup, as he observed that there were no dirt-eating children who would actually be affected because the area was currently unoccupied swamp land..$^{75}$

Setting aside all cost considerations, the pattern of risk perception biases leads people to much prefer eliminating a risk to reducing a risk by the same amount to a low level. A remaining small risk looms much larger than it actually is. The quest for a zero risk level, rather than a risk reduction that bears a reasonable relation to the costs, becomes the objective. In practice, government policies often institutionalize this targeting of a zero risk level. A widespread practice throughout the federal government is to design regulatory policies that do not simply reduce the risk, but also provide an "adequate margin of safety" below the safe exposure level. Agencies are not entirely to blame for the adequate margin of safety concept, as these requirements may also be incorporated in the laws governing regulatory policy. For example, the congressional drafting of the Clean Air Act led to a law that requires the EPA to set ambient air quality standards that provide for an adequate margin of safety below the safe exposure level. ${ }^{76}$ This approach of erring on the side of more safety than is warranted by the presence of a nonzero risk level is also reflected in the Food and Drug Administration's (FDA) desire to ensure that pharmaceu-

73. See STEPHEN BREYER, BREAKING THE VICIOUS CIRCLE: TOWARD EFFECTIVE RISK REGULATION 11-12 (1993).

74. 900 F.2d 429 (1st Cir. 1990).

75. BREYER, supra note 73 , at 12 .

76. See 42 U.S.C. $\S 7409(b)(1)$ (2012). 
tical regulations provide an adequate margin of safety. ${ }^{77}$ Likewise, the Department of Agriculture seeks to provide for a margin of safety in its food safety efforts. ${ }^{78}$

The level of the risk is also consequential in terms of how people respond to changes in a risk. Increases from the accustomed risk level tend to generate extreme responses. Consumers encountering increases in their accustomed risk level for products tend to respond in an alarmist manner. ${ }^{79}$ These responses in turn create pressure for alarmist government regulations. The mechanism driving this result is as follows. Going from a zero risk to a positive risk level moves the individual from a zero risk baseline to a situation of overestimating small risks. Thus, the perceived change in the risk is greater than it actually is, given the low probability. Newly discovered risks in food and beverages provoke strong reactions as evidenced by the dramatic impact of the presence of benzene found in Perrier water in $1990 .^{80}$ Government policies likewise frequently exhibit very strong responses to newly discovered risks. A prominent example is the stringent government responses to the outbreak of bovine spongiform encephalopathy (BSE), known as mad cow disease. The U.K. government may have overreacted by ordering the indiscriminate slaughter of thousands of cattle rather than testing the cattle to assess potential risks. Another example of excessive reactions to the mad cow crisis was Japan's ban on the importation of U.S. beef because of the exaggerated threat that U.S. beef posed. Unlike the United Kingdom, which had as many as 37,280 BSE cases in a single year, the

77. See Preclinical Considerations, FOOD \& DRUG ADMINISTRATION, http:// www.fda.gov/ohrms/dockets/ac/03/briefing/3976B1_02_F-FDA-Tab\%205.pdf [http:// perma.cc/QKF8-Z2BX]; Nonclinical Safety Evaluation of Drugs or Biologic Combinations, FOOD \& DRUG ADMINISTRATION (March 2006), http://www.fda.gov/OHRMS/ DOCKETS/98fr/05d-0004-gd10002.pdf [http://perma.cc/C5HU-MUSR].

78. See Appendix B: Compliance Guidelines for Cooling Heat-Treated Meat and Poultry Products (Stabilization), U.S. DEPT. OF AGRICULTURE (updated June 1999), http://www.fsis.usda.gov/OPPDE/rdad/FRPubs/95-033F/95-033F_Appendix\%20B.htm [http://perma.cc/GN8Z-6RTB].

79. See VISCUSI, supra note 16 , at 127.

80. George James, Perrier Recalls Its Water in U.S. After Benzene Is Found in Bottles, N.Y. TIMES, Feb. 10, 1990, http://www.nytimes.com/1990/02/10/us/perrier-recalls-itswater-in-us-after-benzene-is-found-in-bottles.html [http://perma.cc/UWH3-84BA]. 
U.S. death toll was very low. ${ }^{81}$ In a similar overreaction, the 2014 Ebola threat led to the temporary closure of some U.S. schools as a precautionary measure that appeared to be disproportionate to the actual level of the risk. ${ }^{82}$ In Part V, we discuss many other novel or emerging risks that also entail aspects of risk ambiguity because of their novelty.

It is challenging to assess the soundness of a policy response to terrorism risk. The policy response to the September 11, 2001, attack has been considerable, including increased screening of airline passengers, targeting of passengers based on the perceived risks that they pose, and surveillance of phone calls and emails. These measures surely have had some benefits that are difficult to quantify, but they have also generated some costs to civil liberties and privacy..$^{83}$

The difficulty posed by small probabilities such as terrorism risks is that, because the threats are fairly new, there is not a sufficiently extensive body of data that can be used to assess the risks. The level of these risks has escalated since before September 11, when most people would have assessed the risks as close to zero. The pertinent information gained from the postSeptember 11 period is not enough to form an accurate risk judgment, given the low probability of terrorist attacks. The most that can be hoped for is that the U.S. Department of Homeland Security and other involved agencies assess the risks in a reasonable manner and do not fall prey to the tendency to display an exaggerated response to increases in risk. Unfortunately, it is not feasible to assess the influence of such biases, as the regulatory impact analyses for homeland security policies tend to lack the level of detail needed to determine whether these policies represent judicious responses to a hazard or are a reflection of public pressures that foster excessive

81. There were only three reported U.S. cases from 1989 to 2013. Joseph E. Aldy \& W. Kip Viscusi, Risk Regulation Lessons from Mad Cows, in 8 FOUND. \& TRENDS IN MICROECONOMICS 301-02 (2013).

82. See Jennifer Steinhauer, In U.S., Fear of Ebola Closes Schools and Shapes Politics, N.Y. TIMES, Oct. 19, 2014, http://www.nytimes.com/2014/10/20/us/fear-of-ebolacloses-schools-and-shapes-politics.html?_r=0 [http://perma.cc/9J97-JUQN].

83. See Susan Stellin, Airport Screening Concerns Civil Liberties Groups, N.Y. TIMES, Mar. 11, 2013, http://www.nytimes.com/2013/03/12/business/passenger-screeningsystem-based-on-personal-data-raises-privacy-issues.html?pagewanted=all [http:// perma.cc/EL6K-D2UG]. 
responses. Instead of making a risk estimate, the Department of Homeland Security often relies on a breakeven analysis to assess how great a risk must be to warrant the policy. Given the behavioral biases involved and the general proclivity to overreact to small risks and newly emerging risks, there should be increased attention to the desirability of these policies to the extent that national security concerns permit.

\section{RISK AMBIGUITY AVERSION AND EXCESSIVE REGULATIONS OF DIMLY UNDERSTOOD RISKS}

A common anomaly in risk-taking behavior is the reaction to ambiguous risks, that is, risks whose magnitudes are not well understood. Daniel Ellsberg analyzed this phenomenon, now known as the Ellsberg Paradox, by documenting people's preference for knowing the probabilities of winning a prize. ${ }^{84}$ Subsequent research has documented an analogous phenomenon for losses, as people are averse to the uncertain probabilities whether it is with respect to the chance of winning a prize or the chance of suffering a loss. ${ }^{85}$ In each case, there is aversion to undertaking a lottery that poses an ambiguous risk.

The following example illustrates the phenomenon. Suppose automobile $A$ poses a well-known defect risk of $2 / 1,000$ over the lifetime of the vehicle. Automobile $B$ is newer to the market, and there is a 50-50 chance that the defect risk for automobile $B$ is either $1 / 1,000$ or $3 / 1,000$, generating an expected defect risk of $2 / 1,000$. Each of these cars consequently poses an average defect risk of $2 / 1,000$ and should be viewed as posing equivalent risks. However, people generally exhibit a form of ambiguity aversion that makes the precisely known risk of automobile A less fearsome than the uncertain risk of automobile B.

Ambiguity aversion is a form of irrational behavior and should not be confused with risk aversion in which people are averse to the risk of incurring a large loss. People might quite rationally choose to purchase a homeowners insurance policy for $\$ 1,000$ even though the expected losses are only $\$ 800$. A

84. See Daniel Ellsberg, Risk, Ambiguity, and the Savage Axioms, 75 Q. J. OF ECON. 643,669 (1961).

85. See Colin Camerer \& Martin Weber, Recent Developments in Modeling Preferences: Uncertainty and Ambiguity, 5 J. RISK \& UNCERTAINTY 325, 359-60 (1992). 
very low probability of a catastrophic loss would make such insurance attractive to a risk-averse person and could be quite rational. What would not be rational is to be swayed by the uncertainty regarding the probability. Thus, learning that there is a definite $1 / 10,000$ chance that lightning will hit the house should make insurance just as attractive as having an uncertain risk estimate for which the average risk is $1 / 10,000$.

Government policies frequently reflect this ambiguity aversion with novel risks. For example, court rulings tend to demonstrate a bias against innovation and the attendant uncertainties of novel drug products. In situations where there are adverse health effects from new drugs, the courts are more likely to levy sanctions against the producer. ${ }^{86}$ This bias on behalf of the public is also reflected in product liability case experiments using a sample of judges participating in a legal education program. The judges considered hypothetical cases involving novel drugs and their associated liability risks. When given a choice between a new drug posing an uncertain risk or another drug with a higher known risk, most of the judges recommend that the company market the latter drug. ${ }^{87}$

Another instance of ambiguity aversion involves genetically modified organisms (GMOs), which "are organisms (i.e. plants, animals or microorganisms) in which the genetic material (DNA) has been altered in a way that does not occur naturally by mating and/or natural recombination." 88 GMOs have come under fire and are increasingly subject to potential regulation throughout the world. Engineered corn is a prominent example of a GMO product. Although the regulation of GMOs is more extensive in Europe than in the United States, some U.S. companies have begun labeling foods as GMO-free ${ }^{89}$ In addition, there has been increasing pressure for the government to regulate

86. See W. Kip Viscusi, How Do Judges Think about Risk?, 1 AM. L. \& ECON. REV. 26, 56 (1999).

87. See id. at 57.

88. Food safety: Frequently asked questions on genetically modified foods, WORLD HEALTH ORGANIZATION, http://www.who.int/foodsafety/areas_work/food-technology/faqgenetically-modified-food/en/ [http://perma.cc/24EZ-T935].

89. For example, the Kettle Brand Krinkle Cut Potato Chips have the label "NON GMO Project Verified." THE NON-GMO PROJECT, http://www.nongmoproject.org/ find-non-gmo/search-participating-products/search/?brandId=75 [http://perma.cc/ PWN2-7JMP]. 
GMOs. Prominent consumer-oriented groups such as Consumer Reports are calling for mandatory product labeling of GMOs..$^{90}$ In 2014 some states had ballot referenda to require GMO labeling. ${ }^{91}$ Critics have characterized GMO foods as being very risky products of biotechnology, labeling them "Frankenfoods."92 The policy trade-off involved is that GMOs may pose uncertain risks that currently are believed to be low in magnitude, but they reduce the cost of producing agricultural products, which in turn lowers food prices and promotes better nutrition.

Nanoparticles are very fine particles between one and 100 nanometers in size. These novel components are ingredients in a variety of products, such as sunscreens and polymers. As with GMOs, nanoparticles are on the scientific frontier and pose uncertain risks. They generate potentially substantial benefits but have caused concern among environmental groups. The EPA recently considered a regulatory proposal to require manufacturers of products containing nanoscale chemicals to give prior notice to the EPA before any use of these chemicals, but the agency has since scaled back this proposal to a less burdensome data collection requirement. ${ }^{93}$ The EPA also regulates nearly all new nanochemicals. ${ }^{94}$

The regulatory approach to these and related uncertainties frequently relies on the precautionary principle. Although there are many variants of the precautionary principle, in general the principle places a weight on the worst-case outcome (better safe than sorry) and places the burden of proof on the manufacturer to show that the product is safe. ${ }^{95}$ From a statistical standpoint, the most one can ever do is to reject the null hypothesis of zero

90. See Rebecca Kern, Consumer Reports: GMO Labeling Should Be Mandated on Packaged Foods, 42 PROD. SAFETY \& LIAB. REP. (BNA) 1181 (Oct. 20, 2014).

91. Rebecca Kern, Oregon, Colorado Ballot Measures Among State Efforts to Require GMO Labeling, BLOOMBERG BNA PRODUCT SAFETY \& LIABILITY REP. 42 PSLR 1181 (Oct. 20, 2014).

92. See generally HENRY MILLER \& GREGORY CONKO, THE FRANKENFOOD MYTH: HOW PROTEST AND POLITICS THREATEN THE BIOTECH REVOLUTION (2004).

93. See Pat Rizzuto, Narrow TSCA Proposal on Nanomaterials Sent to OMB in Place of Broader EPA Rule, 42 PROD. SAFETY \& LIAB. REP. (BNA) 1149 (Oct. 9, 2014).

94. See Pat Rizzuto, Nearly All New Nanoengineered Chemicals Are Regulated by EPA Due to Potential Risks, 42 PROD. SAFETY \& LIAB. REP. (BNA) 1183 (Oct. 16, 2014).

95. See Cass R. Sunstein, Beyond the Precautionary Principle, 151 U. PA. L. REV. 1003-04 (2003). 
risk rather than proving that something poses zero risk. Moreover, even extensive testing addresses only the presence of imminent hazards. The fact that there is no evidence of a nonzero risk based on current testing does not preclude the potential for risks that might emerge after a latency period. An example of such deferred risks is the hazards associated with drugs given to pregnant women. One such drug is diethylstilbestrol (DES), which first caused birth defects in the children of mothers who took the drug and then caused second-generation birth defects in the babies of the children of the mothers who took the drug. ${ }^{96}$

Government policies frequently err on the side of safety by avoiding uncertain risks, thus reflecting the biases found among individuals. We advocate instead that the mean risk should be the guide for single-period policy decisions. In situations of learning and potential adaptive behavior, the bias should be in favor of the uncertain prospect. If, for example, the uncertain drug proves to be beneficial, the patient can continue to use it. If the drug has an adverse effect or is ineffective, the patient can switch to an alternative drug. This desirability of ambiguity holds as well in situations where the risk of the adverse outcome is death. ${ }^{97}$

\section{BEHAVIORAL RESPONSES TO REGULATIONS}

Government regulations generally do not dictate policy outcomes. Rather, they establish requirements and incentive structures that may or may not generate the intended results. Despite the government's interest in behavioral economics issues, policymakers often seem to overlook the crucial role of this intermediate behavioral response.

People respond to changes in prices, whether they are due to government policies or to markets. Demand curves for products are a downward function of the price. Should consumers, for example, devote their resources to buying organic fruits

96. NAT'L CANCER INST., DieThylstilbeSTROL (DES) AND CANCER, http:// www.cancer.gov/cancertopics/factsheet/Risk/DES [http://perma.cc/EA9Z-MEHZ].

97. These issues are explored in greater detail in W. Kip Viscusi \& Richard J. Zeckhauser, Regulating Ambiguous Risks: The Less Than Rational Regulation of Pharmaceuticals, J. LEGAL STUD. (forthcoming) (SSRN, Working Paper No. 2392070, 2014), http://papers.ssrn.com/sol3/papers.cfm?abstract_id=2392070 [http://perma.cc/QR8XLZ3S]. 
and vegetables in order to reduce the cancer risk from pesticides? Although affluent consumers may not be price sensitive, the greater cost of organic food products may encourage consumers to have fewer fresh fruits and vegetables in their diet. For this reason, cancer researchers suggest that it is more important from a cancer reduction standpoint to consume fruits and vegetables than to be concerned with the relatively minor risks from pesticides on nonorganic produce. ${ }^{98}$

In some instances, the failure of people and firms to take the actions desired by the regulators arises from inadequate incentives to comply with costly regulations. The entire set of standards initially enacted by the Occupational Safety and Health Administration (OSHA) involved safety requirements that imposed costly expenditures for firms to come into compliance. However, the enforcement accompanying the sometimes rigid standards involved low probabilities of inspection coupled with modest fines, giving firms very little incentive to comply with the regulations. The many studies documenting the negligible or modest effect that this agency has had on safety often trace its poor policy performance to inadequate incentives to lead firms to comply with the standards. ${ }^{99}$

However, even if compliance is ensured, there may be counterproductive behavioral responses. One type of behavioral response can be traced to the way in which regulations alter the benefit-cost trade-offs that people face. For example, the use of automobile seat belts lowers the expected accident costs to drivers compared to what they would be in the absence of seat belt use. Once buckled, however, the safety provided by the seat belt gives drivers a greater incentive to drive faster to reduce travel time, thereby diminishing the beneficial effect of the seat belt requirement and potentially leading to greater numbers of deaths of pedestrians and motorcyclists. ${ }^{100}$

A related phenomenon linked to individual misperceptions is the lulling effect of government safety measures. For in-

98. See Bruce N. Ames et al., Ranking Possible Carcinogenic Hazards, 236 SCIENCE 271, 273 (1987).

99. See, e.g., W. KIP Viscusi, Fatal TRAdeoffs: PubliC and PRIVATE ResPOnSIBILITIES FOR RISK 198 (1992).

100. See Sam Peltzman, The Effects of Automobile Safety Regulation, 83 J. POL. ECON. 677, 677 (1975). 
stance, regulators often tout as "childproof" the safety caps for potentially dangerous products such as prescription drugs and automobile antifreeze. Some parents, believing that the caps will protect their children from exposure to these hazards, have become more lax about safety. The result has been an increase in child-related poisonings that in some cases has offset the beneficial effect of the caps. More generally, the reduced precautions resulting from the behavioral response to the caps has muted the effect of the caps so that there is no evident benefit from the regulation in reducing child poisonings. ${ }^{101}$

Although government agencies have not acknowledged the existence of a counterproductive impact of safety caps, private companies have been more cautious. Before introducing childresistant devices on cigarette lighters, Bic commissioned a field study to ensure that the device would be safety enhancing. Surveyed parents indicated that they would be less concerned about safety in the presence of this safety mechanism. Nonetheless, the field test indicated that, although parents were more likely to give children access to a lighter with the safety mechanism, the safety device was a sufficient deterrent such that on balance the device was safety enhancing. ${ }^{102}$

\section{FAILURE TO EXPLOIT BEHAVIORAL INSIGHTS}

Exploiting the insights derived from behavioral economics can indeed advance the regulatory response to market failures. For example, the externalities of carbon emissions are highly dependent on individual decisions about energy usage, which are influenced by information on peer comparisons; ${ }^{103}$ patients ${ }^{\prime}$ adherence to taking prescribed drugs affects health care costs; $i^{104}$ and people's responsiveness to evacuation warnings affects the losses from natural disasters. ${ }^{105}$ The menu of policy

101. W. Kip Viscusi, The Lulling Effect: The Impact of Child-Resistant Packaging on Aspirin and Analgesic Ingestions, 74 AM. ECON. REV. 324, 326-27 (1984).

102. See W. Kip Viscusi \& Gerald Cavallo, Safety Behavior and Consumer Responses to Cigarette Lighter Safety Mechanisms, 17 MANAGERIAL \& DECISION ECON. 441, 450 (1996).

103. See Ayres et al., supra note 60.

104. See Niteesh K. Choudhry et al., Full Coverage for Preventive Medications after Myocardial Infarction, 365 NEW ENG. J. MED. 2088, 2093 (2011).

105. See Matthew E. Kahn, The Death Toll from Natural Disasters: The Role of Income, Geography, and Institutions, 87 REV. ECON. \& STAT. 271, 283 (2005). 
options sometimes includes attempts to exploit the role of individual behavior, but opportunities to capitalize on the role of behavioral linkages are often not fully recognized.

The labeling policy for motor vehicles discussed above illustrates the potential use of a behavioral approach to foster the regulatory objective of energy conservation coupled with a lack of confidence in its efficacy. In 2011, the EPA instituted a new labeling system for automobile fuel efficiency that would convey information to consumers about the private energy costs of the vehicle as well as the social consequences in terms of traditional polpollutants and greenhouse gas emissions. ${ }^{106}$ Undertaking focus group studies as in EPA's study of energy efficiency labeling is not a substitute for scientific tests of the likely efficacy of labels, as they only provide an informal group that is subject to the influence of the discussion leader and particularly influential participants, a phenomenon known as "the loudmouth problem."107 After mandating a new labeling rule, the EPA subsequently issued mandatory fuel efficiency requirements without considering the effects of the labeling rule, thus resorting to a command-andcontrol approach. In effect, the agency displayed an implicit lack of confidence in behavioral policy mechanisms.

The FDA's proposed graphic cigarette warnings also reflect an underlying lack of confidence in policies about warnings that are in the spirit of "nudge" interventions. Since 1966 cigarette packs have included mandated hazard warnings. ${ }^{108}$ The content of the warnings has evolved over time, but available evidence indicates that people are well informed of the dangers of smoking cigarettes. Moreover, evidence in the literature indicates that to be effective, warnings must provide new information. Despite this evidence on informed behavior, the FDA proposed a series of graphic warnings for cigarettes in response to a legislative requirement that the agency develop such warnings. This proposal was overturned by the U.S. Court of Appeals for the D.C. Circuit, which concluded that there was not "a shred of evidence" that the graphic warnings

106. See 49 C.F.R. $\$ 575.401$ (2012).

107. PHILIP KOTLER \& KEVIN LANE KELLER, MARKETING MANAGEMENT 102 (14th ed. 2012).

108. For a history of cigarette warnings, see generally W. KIP VISCUSI, SMOKING: MAKING THE RISKY DECISION (1992). 
would lead to any reduction in smoking prevalence rates, even based on the agency's own regulatory impact analysis. ${ }^{109}$ Thus, a regulatory intervention intended to alter behavior in effect ignored the behavioral evidence on its likely efficacy. The court concluded that there would be no apparent benefit to outweigh the infringement on corporate speech caused by the warnings.

\section{ASYMMETRIC ATTITUDES TOWARD GAINS AND LOSSES}

From the standpoint of the benefit-cost analysis framework that we advocate, losses and gains should be treated symmetrically. Thus, if a prescription drug leads to an increase of five expected deaths but also a reduction of ten expected deaths, the net effect is to reduce the number of expected deaths by five.

Such balanced arithmetic may not, however, be consistent with patterns of individual preferences. Losses may loom much greater than gains. A suitable measure of the difference in attitudes between losses and gains is the monetary value associated with the change in the risk. People are willing to pay much less for a reduction in risk than the amount that they require for a comparable risk increase. Thus, they value the loss associated with risk increases much more highly than the gain from risk decreases. Reviews of the gap between the willingness to pay for products and environmental goods and the counterpart willingness to accept values for losing these same products or environmental goods indicate average ratios of willingness to accept to willingness to pay as high as 7 in one comprehensive review ${ }^{110}$ and 6.23 in a similar study. ${ }^{111}$

This type of phenomenon is embedded in government policies for products with competing risk effects, such as prescription drugs. The emphasis on adverse consequences is incorporated in the Hippocratic Oath: Primum non nocere, or, first, do no harm. This emphasis sets the tone for regulation by the FDA. If the starting point is to avoid harm, then there will be a

109. R.J. Reynolds Tobacco Co. v. FDA, 696 F.3d 1205, 1219 (D.C. Cir. 2012).

110. John K. Horowitz \& Kenneth E. McConnell, A Review of WTA/WTP Studies, 44 J. ENVTL. ECON. \& MGMT. 426, 428 (2002).

111. Tuba Tunçel \& James $\mathrm{K}$. Hammitt, $A$ new meta-analysis on the WTP/WTA disparity, 68 J. ENVTL. ECON. \& MGMT. 175, 181 (2014). 
greater emphasis on losses than on gains. This approach will lead to the failure to approve drugs that on balance may enhance health but have competing effects.

The reluctance to provide such approval is particularly great when the losses and gains arise in a quite different manner. If the FDA approves a drug that leads to harm, that is an error of commission. If comparable expected harms result from the FDA failing to approve a drug, that is an error of omission, and these losses will tend to receive less weight. Notably, the losses often are more visible in the case of errors of commission. The patients who die after taking a dangerous drug are identified lives. By contrast, the patients whose lives are lost because they failed to get the benefits of a promising new drug often cannot be identified. Most of us do not know which diseases will affect us, so the small probabilistic stake that each of us has in a drug that might or might not help us in the future dampens our concern with its availability. Sometimes, a well-defined patient constituency that can lobby for differential treatment can overcome this insufficient attention to beneficial new drugs with competing risk effects. For example, after vigorous lobbying by AIDS groups, the FDA put patient access to these drugs on a faster track.

\section{INCONSISTENT TRADE-OFFS}

A potential source of individual irrationality is a lack of consistency in decisions across different domains of decision. Obtaining a payday loan at highly inflated interest rates rather than exploiting one's remaining line of credit on a credit card might, for example, be a signal of a consumer's financial irrationality if the consumer could obtain the needed funds at a lower cost. Behaving in an inconsistent manner makes the consumer worse off by imposing additional finance costs and taking away funds that the consumer could have used to advance personal welfare.

The counterpart inconsistent preference problem is potentially of greater consequence for Congress and government agencies. Unlike the textbook consumer, who is assumed to have a single set of preferences, there is no single set of preferences guiding government policies. Members of Congress often advance their narrowly defined parochial interests, as evidenced by the "bridge to nowhere" and other pork barrel projects that bring resources back to the congressperson's home district. 
Similarly, different agencies are not guided by a well-defined national interest but have specific legislative mandates. The result is that agencies tend to develop tunnel vision whereby the particular policy concerns of the agency are of dominant interest. The Clean Air Act's complete disregard for costs in setting ambient air quality standards is perhaps the most extreme example of institutionalized myopia. Unfortunately, tunnel vision is not unique to air pollution regulations. The U.S. Supreme Court has rejected efforts to require OSHA to undertake policies that balance benefits and costs because the agency's legislative mandate requires that the agency ensure worker safety if doing so is feasible, irrespective of the cost. ${ }^{112}$

The rampant inconsistency in government policies is exemplified in the widely varying costs per expected life saved across government agencies. ${ }^{13}$ Although there have been several tallies of such costs, here we will focus on the Office of Management and Budget listing that U.S. Supreme Court Justice Stephen Breyer highlighted in his commentary on regulatory policies. Rather than spending the same cost per life saved in different domains, the costs often vary quite widely. The regulations from the Department of Transportation tend to be quite cost-effective, with costs per life saved on the order of $\$ 3$ million or less per life saved. However, at the high end are regulations such as the EPA hazardous waste listing for wood-preserving chemicals, with a cost per life saved of $\$ 5.7$ trillion. Also at the high end is the EPA Superfund program, which has a median cost per case of cancer averted of $\$ 6.4$ billion. ${ }^{114}$ Of course, in these extreme cases, the agency is not in fact spending billions on the particular policy option. But when the expected lives saved denominator is very small because of the negligible safety benefits of the policy, the cost per life saved figure escalates.

These wildly varying levels of efficacy highlight clear-cut opportunities to make government policies more rational. We make two principal observations. First, these vast differences in cost effectiveness demonstrate that, for the same level of costs,

112. See Am. Textile Mfrs. Inst. v. Donovan, 452 U.S. 490, 491 (1981).

113. The rationality reference point is for the marginal costs per life saved to be equated across policy domains. Available data are generally in terms of average costs per life saved, which also are instructive in that they highlight clear-cut inefficiencies.

114. HAMILTON \& VISCUSI, supra note 69 , at 125. 
government policies could save more lives by redirecting comparatively ineffective regulatory expenditures to agencies that have lower costs per life saved for their regulations. Second, there are real opportunity costs to wasteful expenditures. Funds that are squandered on ineffective policies could be used instead by consumers to promote their well-being. Indeed, because having additional financial resources enhances one's health, there is a health risk trade-off associated with inefficient regulatory policies, so that on balance such policies may be harming health rather than enhancing it. ${ }^{115}$

\section{CONCLUSION}

In recent years, there has been a shift in the traditional economics approach of justifying government interventions based on the existence of market failures such as externalities, public goods, asymmetric information, and market power. Influenced by psychological studies that find systematic biases in how individuals make decisions, the field of behavioral economics has led to recommendations for government policies. These recommendations frequently come in the form of soft regulations or "nudges," to correct behavioral shortfalls that lead individuals to make decisions that cause themselves harm.

The behavioral economics findings that document systematic anomalies that lead to irrational decisions are important contributions to the field of economics. While these biases can be justifications for government intervention, our evidence suggests that a framework of behavioral public choice should take into account that policymakers and regulators are themselves behavioral agents subject to psychological biases, and further, that they are public agents subject to political pressures and biases endemic in the political process. The behavioral paradox is that government policies are subject to a wide range of behavioral failures that in many cases become incorporated in the overall policy strategy. We have documented many instances in which government policies institutionalize rather than overcome be-

115. For a discussion of the various risk-risk models in economics, see W. Kip Viscusi, The Value of Individual and Societal Risks to Life and Health, in 1 HANDBOOK OF THE ECONOMICS OF RISK AND UNCERTAINTY 385, 432-35 (W. Kip Viscusi \& Mark J. Machina eds., 2014). 
havioral anomalies, and in some cases, attempt to justify inefficient "hard" regulations, such as mandates, based on the weakly supported need to correct individual irrationality.

Given that government policymaking is not immune to behavioral failures, we suggest a more cautious approach, one that incorporates the insights of behavioral economics in a way that is less dismissive of the merits of individual choice. Rather than assuming that any class of behavioral anomalies constitutes a sufficient rationale for overriding consumer preferences, government agencies should assess the empirical prevalence and magnitude of the behavioral failings as they specifically pertain to the policy context. If there are apparent anomalies, there should also be an exploration of whether these deviations from economics norms stem from legitimate differences in preferences or are in fact errors that, if corrected, would enhance welfare. Thus, in the design of subsequent interventions, there should be increased recognition of the legitimate differences in consumer preferences that may account for purported behavioral failings. Policymakers should also recognize the behavioral failings likely to be incorporated in their policy responses due to public pressure or the behavioral failures of policymakers. Fundamental behavioral failures are often embedded in the current policy strategies. Any critical review of private behavioral failures should be accompanied by a comparable assessment of government failures. 
